\title{
Managing power in organizations: the hidden history of its constitution
}

\section{Stewart Clegg}

\section{Introduction}

Management as a practice of power involving the imposition of will is directed at framing not only the conduct of others but also oneself. It is a form of government linking 'how to mandate’ with 'how to obey'. Managing implies power because it involves governing the conduct of oneself and others. Managing in any epoch will be a particular skill that involves execution and doing. It will be active, a practice. Moreover, it will not merely be a practice of the self—one doesn’t just learn how to be a manager — but it is also a practice of the many others who are to be managed. Others must learn to be managed just as those who will manage them must learn that which constitutes managing in any given place and time.

While managers originally were constituted as the delegated 'servants' of 'masters', and indeed various Masters and Servants Acts still frame employment relations, modernity saw servants become employees. In US English, Jacques (1996: 68) tells us that the term employee first occurs in the context of a discussion of the railways in which context it stays until the 1870 s, when it started to be used more generally. By the early years of the twentieth century employee had become the accepted and most commonly used term, carrying a weight of semantic meaning: being a permanent worker belonging to an organization; being subordinated; being assigned to tasks to which one is fitted and for which one is paid a wage; being subject to the expertise of a managerial specialist and the panoply of management knowledge, all of which, finally, enables one to become a specialist producer and 
consumer (Jacques 1996: 70-86). The employee was one half of an emerging binary division for which the other half was the manager-a specialist in authorityoverseeing the employee-a specialist in obedience. The division is significant because they both constitute a systemic unity. The worker is power (energy to work), the manager is knowledge (authority by science to conduct behaviours), comprising the essential unity between power-knowledge, the base of modernity (Ibarra-Colado 2001a). What is distinctive about being an employee is that one is presumed, as someone in receipt of a wage, to be an obedient subject, who in return for an income is expected to be responsible to the control of another higher in a chain of command, one of the key concepts of early management theory.

Traditionally, power over those who were subject to supervision was bundled up unequivocally with authority: in the guild system, for instance, the apprentice learnt from a Master, became a journeyman after the period of indenture as an apprentice was completed, and learnt from other Masters whom he encountered in his journeying. Traditional organization meant that there was continuity between task and status structures. One moved up the status hierarchy by displaying mastery of tasks.

In such situations power and knowledge were indivisible: with increased knowledge, in principle, came increased power. Early forms of manufactory did not differ greatly although, as innovations in technology were introduced, the nexus between the operatives' knowledge, the task structure and the status structure began to dissolve. Thus, the emergence of industrial society began to break the nexus between task and status structure and, in doing so, made the power/knowledge relationship in organizations more discontinuous as status and task structures became increasingly 
unaligned as power became embedded in routines in organizations and social programs evolved to buttress power at work.

The use of close supervision of people was very much an engrained habit of pre-modern society, if only because practices of rule were invariably tightly coupled spatially, as the vast majority of people were, literally, placed in a specific locality in a here-and-now that they rarely transgressed or moved away from. For the majority of people life was lived in and around the limits of a walk that might take a day or so to undertake. Being settled they were subject to frequent informal as well as occasional formal scrutiny. Settled life, if it were interrupted, would most likely be because of being pressed into military service of some kind, often literally, as the press-gangs roamed the streets of ports seeking to press available young men into the service of the navy, or recruiting sergeants sought out young village labourers for a life of adventure. Once pressed into service they would meet much more formal management than in the fields or village. They entered an institutional space.

On board ship what they entered was more or less a total institution (Goffman 1961) where they could not escape a particular fusion of power and knowledge, oversight and insight, embodied in the person of the bo'sun. The bo'sun was a boatswain, or petty officer, who controlled the work of other seamen. He knew what was to be done and how it should be done and would ensure that whatever was to be done would be done his way, often using harsh punishment, if necessary, to discipline the recruits. The recruits could not escape-that is what it means to say that they were in a total institution - it was an organizational space that wholly contained them. Their time was enveloped by a single space, that of the ship. Whilst on board they were contained within a disciplinary framework of shifts, work, punishments, and 
provisions that were totally outside their control. The insights of those who managed and handled sailors enabled them to learn skills that they needed for survival in a harsh and dangerous environment. There would be gaps, for instance when the ship docks, those seaman allowed shore leave would gain a temporary degree of freedom. (Of course some were forbidden leave; others may go ashore only under supervision.).

Those who were pressed into military service on land were barely more fortunate. Admittedly, the environment was slightly less total, in the way that a garrison affords more freedom than a ship. Yet, they were more regimented. Being regimented meant not only assuming a regimental identity and the uniform that went with it; it also meant learning a uniform mode of behavior, taught through drill (on which see Foucault 1977).

There are some scholars who suggest that the main basis for early management ideas came from the lessons learned in such garrisons, especially as it pertained to the assembly and disassembly of muskets and the drilling of soldiers in the use of these and other weapons on the parade ground (Dandeker 1990). These methods were first applied to muskets by French gunsmiths, and brought from France to the United States at the time of the American Revolution, where they led, in a way mediated by Charles Davies’ position at the West Point Military Academy, to the 'disciplining' of America through the new science of engineering, in which F. W. Taylor was to play a key popularizing role. ${ }^{1}$

\footnotetext{
${ }^{1}$ Hoskin and Macve (1988) note that from 1817 up to the 1840s, West Point was the prime conduit from France to the US through which the emergent disciplines of mathematics and engineering were introduced to US practice. It was, throughout that period, America's leading engineering and scientific school, and both the material taught, and the pedagogy used to deliver the material, derived initially from the French model of education developed in the late $18^{\text {th }}$ century at the École Polytechnique. French techniques, in turn, have their roots in the methods pioneered by the masters of the Venetian Arsenal in warship building and crossbow manufacture.
} 


\section{Managing bodily order at work}

Frederick Winslow Taylor produced the first modern technology of power, one oriented to constituting a political economy of the body. In an ideal organization, one constructed according to the principles that Taylor advocated and as they were to be developed subsequently, people did exactly what they were supposed to do. Innovation was not favoured; instead, strict obedience to the plan was rewarded. As far as one is concerned with management, the maturation of modernity is marked, programmatically, by Taylor, for he was responsible for creating the individual and responsible employee not just as a creature of religion such as the Protestant ethic —or habit—but as a consciously designed utilitarian project. ${ }^{2}$ Taylor's (1911) preface to The Principles of Scientific Management makes this quite clear when he stresses the need for national efficiency. His utilitarianism can be seen in a number of characteristics of his thought. First, it is teleological in its orientation to means. What is important is securing the desired consequences. Second, in Taylor's philosophy, actions can be judged only by their consequences, such that a dogged empiricism is allied to an unquestioned grasp of the ends to be served. Third, ends are defined in terms of efficiency (primarily for the factory owners) but are represented as the common good. Taylor took utilitarianism from a program for dealing with the marginal and abnormal, the other, and transposed it into a program for dealing with the everyday and the normal, the worker.

\footnotetext{
${ }^{2}$ Taking etymology as a guide, it seems that there is something distinctive in the emergence of management as a characteristic of the modern era, an era that literally means 'of our time'. The literal meaning is too imprecise, however. More specifically, one can think of modernity as a specific quality that first emerged in Western civilization (Sayer 1991). In general, it is a period of time and a quality of culture that the world has been experiencing for at least the last two centuries. While there are many different ways of dating, defining, and characterizing modernity, we will take the modern world as being born at the point where the individual emerges as a conscious reflecting and reflected subject opposed to the 'universal, social body of customs and laws' (Kolb 1986: 67). Bauman (1997: 1) characterizes modernity as an obsession with order. Modernity, among other things, represents the cutting off of the individual from traditional ways of life; it inscribes the use of reason to govern and limit uncertainty.
} 
Individual actions were conceptualized as entailing a whole within which comparison and differentiations must be made. Individuals were differentiated from one another; their attributes were to be measured in quantitative terms, their abilities were to be hierarchically arranged. The expected range of normal output at work was to be codified and then used as a mechanism of feedback, enforcement and further normalization. Through fusing an economic function with one that is social, the organizational workplace became a huge laboratory for the perfection of techniques of management. Disciplinary programs were created with the power to shape people, to shape work, and to shape the organization's technical and human system. Of course, programs are not projects that are perfectly accomplished—-they are always situated in the future perfect, designs for a world that would be made if there were no obstacles to its unfolding as such. Yet there are always such obstacles, always resistance to the projects of power, always unanticipated consequences of social action. In many ways these resistances, these imperfections in specific power projects, only serve to heighten the resolve and the perception of need for the failed project to try again. The problems that it was designed to address are evidently still there and so the project needs to be revised, perfected and enacted again ... and again. It is this recurrence that comprises the specific nature of management knowledge, a set of savoirs produced by everyday practices of power. The power that is at work in programs of management, a pragmatic science of immediate practical consequence shaping the existence of people in their everyday life, is highly specific. It is not merely a repressive or prohibitory power; it does not just involve the possibility of imposing one's will upon the behaviour of other persons through prohibiting behaviour that they would otherwise normally be disposed to. Rather, it works in a more positive way by shaping the dispositions that define what we take, normally, to be true. The calculations subjects 
make about effort, disposition, and demeanour, for instance, are both subject to, and resources for, this pragmatic science. Managing means constituting central aspects of identity through relations of power; thus, when one is managing this implies that one is exercising power-over both other people and things. Managing means making things happen through the exercise of initiative and agency-and that means power.

Taylor's concern with productivity and performativity provided the intellectual and social context within which management was first defined. It was a context riddled with power at every turn. Assumptions about the natural order of things underlay Taylor's idea that some were born to manage and direct, while the fate of others was to be managed and directed. Efficient management was based on reforming power/knowledge relations, taking them out of the hands of the workers and systematically refashioning them so that they could be placed in the hands of management. Once these reformed relations were in management's remit then managers would be obliged to obey the precepts of science and respect a liberal mentality, much as should efficient employees in general. Once the one best way was devised, any deviation from it should be regarded with anathema. The purity of power consisted in its eternal return as repetition, as the same routine.

Power-getting others to do what one wanted them to do, even against their will—was inscribed as the normalcy of the new system of scientific management. In this system one should always do just as one was told; one should never be where one does not belong, and what one should do and where one should be were not to be left to chance but should be determined, authoritatively, by the science of productive efficiency and management. The new system of rule could be denoted as a regime of impersonal authority which served no interest other than the general interest in 
utilitarian efficiency, an interest from which all, with the exception of lazy people who refused to change their behaviour, might prosper. The poor but honest labourer could enrich himself through the dignity of his own exertions in a system designed to maximize the rewards that flowed. So could the employer in the counting house, amassing profits from the same principles. In principle, all would be for the best in the best of all possible worlds.

After Taylor, the individual workman need not exist merely as a creature of habit, tradition or craft but could become an object of scientific knowledge and a subject produced by the application of that knowledge. The worker became a utilitarian subject. Taylor marks a significant break not because he was some unique innovator or discoverer of truths previously unknown but because he popularized ideas that, although they had been practiced previously, had not been collected, synthesized, documented, and marketed as specific ways of intervening into the everyday organization of work. They had not been ‘made up’ into a bundled program, designed to regulate conduct and to order the spaces within which things are thinkable, utterable, and doable. It was the achievement of this that marks the emergence of modern management as the application of rational means to everyday practice and measurable ends.

Taylor's utilitarian calculus was oriented to the problem of making employed, rather than idle, hands busier in the service of the greatest good of national efficiency and for the better reward of both hands and the businesses that employed them. In fact, one of Taylor's biographers, Kanigel (1997), suggests that efficiency became iconic for almost all American organizations, and increasingly, those of other industrialized nations. It had to be worshipped, feted, and widely represented in 
cultural artefacts of the age. Taylor's (1911) Principles of Scientific Management was such an artefact. It helped persuade people that efficiency was desirable as an end in itself and that all legitimate means should be oriented towards it.

A key feature of Taylor's work was use of a stopwatch to time his observations of work - in a less than perfect attempt to impose exactness - whose accuracy was later to be improved greatly by the use of film by some of his associates. In many respects, Taylor was an acute, if somewhat one-dimensional, ethnographer. Taylor was a detailed chronicler of life in the factory. He wanted to know exactly how workmen did what they did when they worked, which entailed detailed ethnographic observation, for which he developed a system of denoting and coding. However, it was an ethnographic method devoid of understanding and input from the subject it objectified.

Taylor's ethnographic interests were not anthropological; he did not wish merely to describe accurately the customs and rituals of those whom he encountered in work but sought to reform the nature of that work, guided by a concern only to increase efficiency. He sought to redesign work so that it was conducted in the most efficient way that he could imagine, based on his detailed empirical ethnographies and timings of how it was actually done, as well as how it might be done differently, according to his redesign. The approach constituted management as a science premised on the dangerous conviction that a single view, based on efficient ends, was to be esteemed above any grasp of interpretive understandings that might be found in the context being studied.

Taylor stressed three techniques in the design of work. Empirical examination, division of labour, and individual competition were his themes for the analysis of 
work in the factory. Examination was conducted through the detailed observation, note taking and timekeeping of the methods engineer. The redesigned work that would flow from this close inspection and examination was premised on a radical division of labour, with a strict separation between the mental labour of oversight, intended to see the strict dictates of the system were followed, and the manual labour of the production worker, which followed the formalized plan of the engineer. Finally, each individual employee competed against all other employees to maximize the pieces that they could make and thus the piece rate that they could earn such that they could become a 'high-priced man’ (Taylor 1911: 60)

Timing and redesign were the panoptical mechanisms that Taylor designed. All work practice were subject to hundreds of observations and timings, through which he sought to establish what he thought of as the one best way in which to do any given task. Taylor's primary objective in doing a time study was to ascertain an appropriate production rate to use as a basis for an incentive payment. What he sought was the fastest rate and then he wanted to be able to decompose its elements so that he could understand how it was possible, and how it could become the standard for all operatives.

Expensive measurement and observation instruments and pre-printed notepads were used to develop the standards. Observations were made with care for precision, up to a thousandth of a minute in some cases. Taylor compartmentalized productive activities into elements. For each job, elements were defined in such a way that activity within the element could not easily be interrupted. They were the microcomponents of work, the smallest unit of task time complete in themselves. 
Taylor's procedure made time study much easier, making it possible to produce detailed descriptions for production planning, using the central notion of standard data. If elements were properly designed, according to Taylor's rules, it became possible to determine a standard for the process by describing the process in terms of its pre-rated elements. Taylor's system was based on a standardized description of every job, abstracted from what was determined as the 'one best way', then recorded on cards and filed, and used as the measure for anyone doing the task in question. A lack of task variability and the repetitious nature of the tasks involved in the occupations studied extended the usefulness of the approach.

The innovation with which Taylor is most associated is the linking of efficiency to power through the medium of the human body. The program sought to drill efficiency into the nature of being, starting with the individual body (anatomical politics), moving to the collective body of/in the organization (bio politics), and generally percolating into the societal body by economizing society (social politics), all in the name of efficiency.

Efficiency means achieving desired effects or results with minimum waste of time and effort; through minimizing the ratio between effective or useful output to the total input in any system. It was Taylor's practical experience, rather than theoretical knowledge gained from engineering, that enabled him to begin the enquiries for which he became famous. These started with a practical problem of how workmen might best use lathes to cut metal when they were powered by the new invention of electricity. As Jacques (1996: 105-106) notes, Taylor's innovations with the lathe were a result of applying mathematics, creating quantitative tables, and using slide rules to shape new practices. 
The central focus of Taylor's system was the body of the individual laborer and its relation not only to other bodies but also to the material artifacts that formed the labourer's immediate work environment. What Taylor produced may be characterized as a political economy of the body. ${ }^{3}$ As such, Taylor was the symbolic icon and the visible point of an epoch and a mentality. In this way, the overall contribution was made by a broad movement in which several individuals made an important contribution building this management of bodies (Taylor, of course, but also the Gilbreths, Münsterberg, Gantt, and others who responded to the structural conditions provided by the new factory system powered by electricity, by producing new mechanisms for managing bodies in the factory and beyond [see Nelson 1975; Watts 1991]).

Canguilhem (1992:63) points out that Taylorism established a mode of work premised not only on the subjection of the workers' body to the superior intelligence of the managers' mind, but also to industrial machinery. The human body was measured as if it functioned like a machine. For the former, Taylorism represented a working out of Cartesian dualism—-the split between mind and body—as a social relation, as Braverman (1974) was to argue. But it is how this was done that interests us as it was through new disciplines focused on the individual human body that Taylor’s (1911) practice sought to produce its effects. The new disciplines, the subjection of the body to new rigors, were clearly justified by productive economic practices. Foucault defined a discipline as a 'unitary technique by which the body is reduced as a 'political' force at the least cost and maximized as a useful force' (Foucault 1977: 221). It was in this context that Foucault introduced the idea of

\footnotetext{
${ }^{3}$ Even perceptive observers of the body, such as Dale (2001) and Turner (1984) fail to recognize Taylor's contribution in terms of a political economy of the body.
} 
anatomical politics, related to the disciplinary regime of the individual body. It was in this sphere that Taylor's major contributions were made. Taylor was the founder of the discipline dealing with the design of machines and equipment for human use, and the determination of the appropriate human behaviours for the efficient operation of the machines, which has subsequently and variously been called human factors, human engineering, and ergonomics (the latter of which could, in fact, be seen as an example of what Foucault [1977] refers to as 'bio-power'-the government of the social body—while Taylor was more concerned with the management of individual actions rather than the use of knowledge and categorizations to manage populations). Discipline targeted the human body, with the goal of simultaneously exploiting it and rendering it docile and cooperative. For instance, in his experiments with shovels at Bethlehem Steel, Taylor focused on the body of the men; for instance, he told a worker that the most efficient method of shovelling was to put the right arm down by the right hip, hold the shovel on the left leg, and throw the weight of the body forward when digging the shovel into a pile, instead of using the arms and just pushing the shovel into a pile.

What Taylor did was to routinize power. Management intervention, in terms of an explicit exercise of power, was designed to handle situations where routines were not working. These routines were premised on a hierarchy: Organizations should be arranged in a hierarchy, based upon systems of abstract rules and impersonal relationships between different categories of employees. Taylor's framework for organization thus created a seemingly scientific basis for a clear delineation of authority and responsibility, based on a separation of planning from operations, a high degree of task specialization (although this was subsequently to be developed to new heights by Henry Ford), and a system of incentive schemes for workers. Management 
knowledge was designed to order and control what was known, protecting and insuring it against the uncertainty of the unknown, to the greatest extent possible (Yates 1989; Brown and Duguid 2000). The less that management had to exercise power the better power was embedded in the routines.

At the end of the nineteenth century the conditions of possibility for building new practices and knowledge with which to discipline bodies had produced, as we have seen, a new economy of the body. Now, while this was newly applied to factory work, it was not a new occurrence. Foucault (1977: 28) discussed the development of a political anatomy where 'power seeps into the very grain of individuals, reaches right into their bodies, permeates their gestures, their posture, what they say, how they learn to live and work with other people', in relation to earlier forms of drill observed in the bodies of marching soldiers and the posture of school children became cases for analysis. With Taylor, their non-institutionalized parents, if they worked in the factory, could also be reformed through an inspectorial urge.

\section{Managing the moral order}

Hitherto, with Taylor, the regulation of work had stayed within the organization and its disciplinary practices. It soon expanded outside, into the streets, the homes, the bars, and savings accounts of industrial workers. The stimulus was Henry Ford's introduction of the moving assembly line and attempts to ensure that only deserving workers received the high wages that Ford's factories were paying.

In 1913, 30 years after Taylor installed his first system, a revolution in manufacturing occurred when Henry Ford introduced the assembly line as a new way of producing automobiles, modelled on the Chicago slaughterhouses. The assembly 
line of production borrowed heavily from that of death. It vastly simplified production through running at a constant speed by which the workman must measure his pace, so that products are delivered at a constant production rate. Each job on the line had to be completed in an amount of time commensurate with this production rate. Each job became known by a precise description of the task it comprised; however, there were many thousands more jobs involved in the making of a car compared to the killing and butchering of a pig, with the job description manuals coming to resemble telephone directories.

The relations of power in these organizations were shaped by ever more elaborated definitions of routines, embedded less in traditional craft and practice but more in the creation and specification of new workplace relations and routines. They reached their zenith in the new workshops and factories of the automobile industry, especially the Ford Motor Company, which in the 1920s was seen as the very harbinger of what modernity was all about. The power of mass production was seen as the greatest productive power that had been unleashed by the modern world. But behind the glittering automobiles, behind the assembly lines of modern times, there was another more complex and subtle moral machinery of power at work.

While it is important to know how much time each element requires to be accomplished, other aspects of time study techniques were not appropriate for assembly line manufacturing. Individual incentives were not appropriate because every operator was tied to the speed of the line and they were not needed because of the discipline the line imposed. What remained from the Taylor system was the elemental decomposition of jobs. Jobs were small, repetitive and routine. In fact, routine became such a problem among Ford's workers that, in the first year of full 
assembly line operation, the company experienced about 900 percent turnover (see Williams et al 1992). Between October 1912 and October 1913, Ford hired 54,000 workers in order to maintain a work force of 13,000. The annual turnover rate settled at around 400 percent and daily absenteeism ran between 10 and 20 percent. It was for this reason that on January 5. 1914, the Ford Motor Company announced the fivedollar, eight-hour day for all production workers, irrespective of pieces produced (which was determined by the speed of the line anyway, not individual effort). What the company announced was not a plan to pay workers an hourly rate equivalent to five dollars a day but a plan that allowed workers to share in the company profits, which, in principle, would amount to a five dollar day. This represented a considerable sum of money for production work in contemporary terms, doubling incomes and, with the possibilities afforded by hire-purchase, a new innovation, meant that having consumer goods such as cars became something to whose ownership it was feasible to aspire. Ford's innovation reflects the relentlessly upbeat, optimistic, culture of consumption, premised on the five dollar day, which became a significant feature of American life and American world-wide culture.

In 1914 Ford established the Sociological Department to investigate the home lives of workers (Marcus and Segal 1989: 236-8). It was a remarkable example of an ultimately failed attempt to institute meta-routines governing societal politics. The five-dollar day was designed to include only those who were 'worthy' and who would 'not debauch the additional money'. The rules governing eligibility were demonstrating that, if one were a man, one lived a clean, sober, industrious and thrifty life, while women had to be 'deserving ' and have some relatives solely dependent upon them. After a probationary period, subject to a recommendation from their supervisor, worker eligibility would be investigated. About 60 percent were found to 
be eligible. Investigators from the Sociological Department visited workers' homes and suggested ways to achieve the company's standards for 'better morals,' sanitary living conditions, and 'habits of thrift and saving'. Employees who lapsed were removed from the system and given a chance to redeem themselves. Long-term failure to meet Ford Motor Company standards resulted in dismissal from the company.

Meyer (1981) reports a 1917 Sociological Department report. Fifty-two investigators visited 77 districts throughout Detroit and its suburbs. Each district contained an average of 523 workers. Each investigator had an average caseload of 727 workers making 5.35 regular investigations each day, five 'absentee calls' and 15 'outside calls'. For each investigation Ford maintained a record consisting of every available source of information from churches, civic organizations, and the government. The company wanted to know whether or not the worker was purchasing a home, whether he had a savings account and whether he had debt. It required the bank account number, name of the bank and balance of any accounts; for debts, the company needed to know the holder of the debt, its reason and the balance (Meyer 1981: 130).

There was a degree of racism at work in these sociological investigations, paralleling Ford's well-documented anti-Semitism (Lee 1980). After the Civil War, black people had been leaving the sharecropper society of the Deep South in droves, fleeing a culture rooted in slavery. And, after hitting Highway 61, they headed for the burgeoning factories of the north, in Chicago and Detroit, in the latter of which Ford began hiring African Americans in large numbers in 1915, paying them the same wages as his white employees. The material basis of the jazz age for the many black 
people who headed north was provided by working in the factories and assembly plants. By 1923, Ford employed 5,000 Detroit-area black men, far more than in other plants.

The influx of black people into Northern cities and jobs was the occasion for middle-class white anxieties. Indeed, at the time they were a source of what Stanley Cohen (1972: 9) has referred to as a 'moral panic'. A moral panic occurs when some 'episode, condition, person or group of persons' is 'defined as a threat to societal values and interests'. Such moral panics are based on the perception that some individual or group, frequently a minority, is dangerously deviant, and poses a menace to society. They often occur as a result of a fear of a loss of control when adapting to significant changes. Typically, as Cohen suggests, authorities create 'stylized and stereotypical' representations, raise moral fears, and 'pronounce judgment'.

Moral panic fed in to the work of Ford's Sociological Department. They wanted to ensure that Ford employed were sober, disciplined men, whose energies would be conserved and their minds wholly focused on the necessity of being excellent five dollar a day men. Workers who wasted money on booze, dope, and vice were not welcome as Ford employees, as members of the Ford family. Decent white folk knew the type of person most likely to be wasteful of their energies and the kinds of excesses in which they would be wasted. African-Americans, jazz, and intoxication of various kinds became inexorably intertwined in the popular imagination of, as well as some experience in, black culture. The scapegoating of black cultures, such as jazz, was emblematic of a deep-seated paranoia. 
Jazz received a fair amount of negative press in the late 1910s and then became the object of a moral panic during the 1920s. Some whites feared jazz because it was rooted in black culture, because it played a role in facilitating interracial contact, and because it symbolized, in racially coded terms, the intrusion of popular tastes into the national culture ... (Porter 2002: 9).

The moral panics that grew in the 1920s and 1930s around 'jazz' were barely coded concerns for the contagion of white society by black bodies and black culture. As Lopes (2005: 1468) suggests, from the Jazz Age of the 1920s 'the sordid world of jazz and the deviant jazz musician became a common trope in the popular press, pulp fiction, and Hollywood film. Jazz in general served as a trope for the darker side of the American urban experience.' For Ford, establishing a Sociological Department (as well as employing Pinkerton's to spy on potential trouble makers and unionists and to break up union meetings) to ensure the moral probity of these new employees seemed a small investment to make to ensure an efficient, reliable and certain workforce, untroubled by an inability to save, invest and consume. Such irrationalities were to be expected of people who made jazz their culture.

It is not surprising that jazz played this role; first, it was associated by respectable white society with unrespectable black society; second, it infused the body with passion, rhythm, movement, and a lack of disciplined sobriety. It was wild dance music and its main feature was its exuberant ability to move its fans and musicians to shake their bodies, dance, and beat the rhythm. As Appelrouth (2005: 1497) suggests, 'manners of the body share the potential for becoming a stage on which the struggle for social legitimacy and control is dramatized'. In the body may be seen the larger social order and its struggles to impose good order, taste and discipline on nature. 
Pollution of the body is a metaphor for the disruption of the boundaries that shape 'legitimate’ society, as Douglas (1996) suggests. Thus, following Appelrouth (2005: 1497) 'we should not be surprised to find anxieties concerning social disruptions expressed through a body-centred discourse. During periods in which challenges are posed to existing social divisions and schemes of classification, attempts to define the body publicly take on heightened significance'. As the Ladies Home Journal saw it,

Jazz disorganizes all regular laws and order; it stimulates to extreme deeds, to a breaking away from all rules and conventions; it is harmful and dangerous, and its influence is wholly bad ... The effect of jazz on the normal brain produces an atrophied condition on the brain cells of conception, until very frequently those under the demoralizing influence of the persistent use of syncopation, combined with inharmonic partial tones are actually incapable of distinguishing between good and evil, right and wrong (Faulkner 1921: 16; from Appelrouth 2005: 1503).

Degenerate brains, an inability to follow rules, and a general lack of moral qualities were not what Mr. Ford required in his employees, so the Sociological Department had much to do as a private moral police for the Jazz age and, even though the Department did not last long, it hardly mattered. After 1921 it was discontinued and rolled into the notorious Service Department, run by ex-boxer and security chief Harry Bennett, who formed it into a private army of thugs and gangsters to terrorize workers and prevent unionization. Ford's Service Department would grow to be the largest private police force in the world at that time. Its major work was spying such that no one who worked for Ford was safe from spies, intent on seeing that the \$5 dollars was not being wasted, both literally and metaphorically.

A trope was at work at this time. The Jazz Age viewed through 'respectable' white eyes was characterized by anxieties about the association of blackness, jazz, 
booze, and dope. The latter was a particularly significant trope, as was alcohol. Despite the fact that, as its name suggests, marijuana first came into the US from Mexico, jazz and marijuana became inextricably linked with black people and black music in the popular imagination. The first recorded use of marijuana in the US was in Storyville in 1909 (Abel 1980), which was the red light district of the port of New Orleans and the birthplace of jazz. Foundational jazz musicians, such as Jelly Roll Morton, honing their craft in the bordellos, created incidental accompaniments to the central commerce conducted there. Rather than drink, dope was the preferred drug. Marijuana didn’t slow down the reflexes and improvisation the way that alcohol could; also it seemed to heighten the creative impulse. Jazz and dope were not exactly the stuff of a rationalizing impulse.

Increasing societal support developed for Ford's 'sociological' and 'service' projects. First in the ranks was the project of Prohibition, the doomed attempt to ban alcohol consumption from a number of US states, which started in 1920, and which Ford had long supported and promoted, also intensified a prohibitory gaze that sought to ensure that employees could resist temptations to vice. In fact, the struggle against liquor was also a struggle against jazz with which it was associated in licentiousness. Gramsci explicitly made the connection to moral panics.

The struggle against alcohol, the most dangerous agent of destruction of laboring power, becomes a function of the state. It is possible for other 'puritanical' struggles as well to become functions of the state if private initiatives of the industrialist prove insufficient or if a moral crisis breaks out among the working masses (Gramsci 1971: 303-304) 
Power in the organization was now effectively buttressed by power in the wider society; in order to ensure the most efficient routines at work, some control over the type of person that was employed was required. Initially, the new power of surveillance over private life was vested in and an extension of the organization; latterly, as Fordist modernity became characteristic of modernity in general, in workshops large and small, the state took over the functions that private capital had hitherto assumed. ${ }^{4}$ Small employers or those new to business could not develop their own Sociological Departments, but the state, as an ideal total moralist, supplemented the work of surveillance over those in whom the churches and associated temperance movements had not succeeded in instilling a governmental soul. Power shifted its focus from the individual to the collective.

\section{Managing the collective soul}

The analytics of power, focused on a political economy of the body, sought to create workers as precision instruments. Task decomposition, the reformation of tasks and their physical undertaking according to methods, and the use of imposed sequences were all important. However, as time passed it became increasingly evident that the body alone was not what was employed at work: the worker's body, to be truly disciplined at work, required disciplining in life. Ford’s Sociological Department went some way towards achieving this. The body, though always individuated, houses a social being; one with a culture and an identity, as well as passions and interests

\footnotetext{
${ }^{4}$ Prohibition dealt with drink, at least until its failure and its creation of a criminal economy was acknowledged by its repeal in 1933. In consequence, the moral panic shifted from alcohol to dope during the 1930s, enacted by the banning of cannabis in seventeen states. The Federal Bureau of Narcotics was established in 1930. In 1937 the Marijuana Tax Act effectively banned cannabis throughout the United States. One presumes that the new intensification of work was a significant reason for the panic, in addition to its association with the moral corruption of white society from black culture. Taylorized and Fordized workers could hardly be both intoxicated by recreational drug use and expect to be the new men of the industrial age, eager to earn their five dollars a day.
} 
transcending the working week. The conceptualization of this managerial problem was a natural progression of the moral projects that sought to reform the employee through political economy aimed at the body. If projects of power were to overcome the limited efficacy of their efficiency concerns to date, then they had to address both body and soul; they had to recognize the place of the being in the body as a social subject.

The Hawthorne Studies provided Mayo with the opportunity to argue that small groups had their own sources of positive power, derived from group morale. When Mayo (1933) looked at the findings from the Hawthorne Laboratory investigations he thought that the results showed that employees had a strong need for shared cooperation and communication. Merely by asking for their cooperation in the test, Mayo believed the investigators had stimulated a new attitude among the employees. The assemblers considered themselves to be part of an important group whose help and advice were being sought by the company. He believed that if consultation between labour and management were instituted it would give workers a sense of belonging to a team. Here we can see the transformation produced in the modes of surveillance. A new strategy of government of the body/soul in the factory was to be based on the construction of a sentiment of freedom (and responsibility) without—apparently—any kind of surveillance:

The improvement in production, they believe, is not very directly related to the rest pauses and other innovations. It reflects rather a freer and more pleasant working environment, a supervisor who is not regarded as a 'boss,' a 'higher morale.' In this situation the production of the group insensibly lifts, even though the girls are not aware that they are working faster. Many times over, the history sheets and other records show that in the opinion of the group all supervision has been removed. On occasion indeed they artlessly tell the observer, who is in 
fact of supervisory rank, very revealing tales of their experiences with previous 'bosses.' Their opinion is, of course, mistaken: in a sense they are getting closer supervision than ever before, the change is in the quality of the supervision (Mayo 1975: 75).

These studies changed the landscape of management from Taylor's engineering approach to the political economy of the body to a social sciences approach that focused on the interior life, the mental states, the consciousness and unconsciousness - the 'soul'—of the employees. Worker productivity would, henceforth, be interpreted predominately in terms of patterns of culture, motivation, leadership, and human relations (Maslow 1978). The locus of power shifted from the engineering expert, designing the job, selecting and training the right worker, and rewarding performance, to the manager, responsible for leading, motivating, communicating, and counselling the individual employee as well as designing the social milieu in which work takes place.

Mayo developed what became known as the Human Relations School. The emphasis of this approach was on informal work group relations, the importance of these for sustaining the formal system, and the necessity of the formal system meshing with the informal system. In the informal system special attention was to be paid to the satisfaction of individual human needs, focusing on what motivates different people, in order to try and maximize their motivation and satisfaction. Mayo thought the manager had to be a social clinician, fostering the social skills of those with whom she or he worked. Workers who argued with their managers and supervisors were expressing deep-seated neuroses lodged in their childhood history.

Therapeutic interviews were recommended as a management tool, to create better-adjusted workers, and training in counselling and personnel interviews was 
touted as an essential management skill. The advice was simple. Pay full attention to the interviewee and make it clear that this is the case; listen carefully to what they have to say; do not interrupt; don't contradict them; listen carefully for what is being said as well as any ellipses in terms of what is left unspoken; try and summarize carefully what has been said by the speaker as feedback for the interviewee, and treat what has been said in confidence (Trahair 2001). ${ }^{5}$

An ideal interview would be a form of confessional, working through positive power. The individual subjects who are interviewed will reveal themselves to themselves through these interviews; 'they will reflexively turn in upon themselves as an object of truth', as Haugaard (1997: 90) suggests, but the presentation of truth will be one which mere employees 'are not competent to interpret so the expert [the manager] is needed to weave a discourse of truth out of their deepest desires and most secret longings'.

The body having been re-engineered it was now time to get to work on the soul—or at least that secular synonym for it—the unconscious. Trained dispositions are disciplined and responsible and will conduct the body through self-control. Mayo contributed to the new technologies of the self and counselling (Rose 1996; also see Baritz 1974). With Mayo, power moves from a focus on the body of the worker to the voice of the worker; the signs of the unconscious that are interpretable through eliciting employee participation in therapeutic counselling. Now, it is evident that this is not a meeting of equals. These sessions are to be neither friendly chats nor a

\footnotetext{
${ }^{5}$ Mayo's intent was clearly manipulative. Contemporary forms of workplace counseling are handled off site, away from work, and confidentially. Mayo's interest in counseling was not about helping employees but helping managers better manage these employees through control and manipulation.
} 
meeting of equals but a meeting of clinical expertise lodged in superior power, claiming the mantel of authority, with human weakness, frailty and illness.

Just as Taylor's focus on disciplining the body was tempered in practice by Ford's concern with the morality of his five-dollar a day workers, so the theoreticians of management shifted their focus from the body to the soul (consciousness and unconsciousness). The locus of the moral being was defined as one who not only is but also wants to be an obedient subject. The self became 'an object of reflection and analysis, and, above all, transformable in the service of ideals ...' (van Krieken 1990: 353). The ideals were only too clear, given that the meta-routine that had already been established was efficiency. What was under construction here was an attempt to establish patterns of spontaneous obedience as similar meta-routines that could be depended on utterly.

Mayo unequivocally unleashed a program for reforming the individual as an object of reflection, analysis, and transformation, and much of subsequent management was to extend this technology of power by normalizing it as simply the constitution of management. Rose (1989:2) noted that the 'management of subjectivity’ became 'a central task for the modern organization' and those who profess expertise about them.

What was crucial about the Hawthorne Studies was that it reconstituted subjectivity not as a unique quality of the individual's psychology but as a phenomenon of the group and a resource for the organization.

The group represented a field for thought, argument, and administration that was genuinely supraindividual and yet not of the order of the crowds or the mass. The group would exists as an intermediary between the individual and the population, it would inhabit the soulless world 
of the organization and give it subjective meaning for the employee, it would satisfy the social needs of the atomic and fragmented self isolated with the rise of the division of labor and the decline of community, it would explain ills and could be mobilized for good, it could bring about damage in its totalitarian form and contentment and efficiency in its democratic form. In the medium of the group a new relay was found where administration in the light of psychological expertise could come into alignment with the values of democracy (Rose 1996: 136).

The attitudes of employees; their feelings of control over their working lives; the sense of cohesion within the work group, and their belief in the good dispositions of bosses and supervisors towards them created 'a range of new tasks' that 'emerged to be grasped by knowledge and managed in the factory’ (Rose 1996: 138). Things that were not known had to be made knowable, to be given shape and form. Nondirective interviews were used to find a 'way into the emotional life of the factory, the emotional significance of particular events in the experience of the worker' (Rose 1996: 139). These could then be slotted into the emergent discourse of functionalism that Parsons and others at Harvard were developing: manifest and latent functions could be distinguished so that one could analyze problems scientifically, in terms of underlying causes rather than apparent explanations.

Human relations approached these matters through more psychobiological constructs, preparing the way for organizational behaviour to emerge as a selfreferential discourse, while functionalism goes on to define contingency theory as the triumph of organization studies. Organizationally, knowledge of existing patterns of relations could be incorporated into change programs to make them more efficacious; interviews could fulfil therapeutic functions by making latent issues manifest. Managers could then manage in full knowledge of those sentiments and values 
belonging to their employees and act upon them appropriately. Specialized functions, such as personnel management, emerge to deal with these issues, through counselling, easing adjustments to change, planning and collecting data. Other new disciplines such as organizational communications also emerge as instruments for realigning misaligned values within organizations. Definitions of the situation could be arrived at that were shared in management's terms rather than being opposed by worker's terms. A culture of commitment could be built. And its builders should be leaders. Groups needed leaders. Leadership prowess was evaluated on the basis of an ability to get others to do what it was that the leaders wanted them to. And when they did this they could be seen to be leaders who cheapened the costs of surveillance greatly (Bavelas and Lewin 1942). Such leaders learnt how to use the democratic potential of groups to manage so that they could relax their vigilance in consequence. Group dynamics, leadership, sensitivity could all become the object of training and the subject of a new disciplinary apparatus that could be forged, just like a science, in the laboratory (Cartwright and Zander 1953).

Political economy shaded into moral economy as the 1930s developed. Slowly, it became evident that efficient routines could only be founded on the social and cultural rehabilitation of the worker as a whole person rather than merely their perfection as an instrument of political economy. The political economy project was doomed by one simple substantive fact. What people ordinarily know and dosometimes in ways that a theory never captures—is essential to how organizations are able do what they do. The one best way could never be entirely prescribed and where it was attempted then, by definition, something close to a non-learning organization would be instituted. Even scientific managers could realize this in the main lesson of 
the Hawthorne studies. It was a realization that became the impetus for Mayo’s moral economy project.

The moral economy project was not really as radical as some of its prophets, such as Mayo, assumed. It built on what Taylor bequeathed. It didn't deconstruct the legacy. Contemporary theory builds on the legacy of both of these schools. In this approach, the ordinary knowledge of ordinary people is regarded as a neglected resource that managers must access, use and routinize. They will do this through the simple strategies of building social capital (brought into focus primarily through the work of Robert Putnam [1993; 1995]) and through the use of those coactive power strategies that Mary Parker Follett recommended for building such capital. Once social capital has been identified, then new routines can be constructed. Social capital takes care of the coactivity while knowledge management will structure the new routines. It is tempting to see the former as a continuation of the concern with the moral economy and the latter as a simple extension of scientific management- to incorporate the mind as well as the body and soul of the employee.

\section{Managing social capital}

Social capital has been defined in management as 'the sum of actual and potential resources embedded within, available through, and derived from the network of relationships possessed by an individual or social unit' (Nahapiet and Ghoshal 1998: 243). Firms are 'understood as a social community specializing in the speed and efficiency in the creation and transfer of knowledge' (Kogut and Zander 1996: 503). Organizations, designed to bring people together for task completion, supervision and coordination, result in frequent and dense levels of social contacts, creating coactive power in Follett's terms. Social capital, as Follett realized, makes it possible for ends 
to be achieved that, in its absence, could otherwise only be achieved at additional cost. $^{6}$

Social capital concept privileges the worker as a 'knowledge worker' with embrained rather than embodied knowledge (Blackler 1995). Such employees are potentially mobile and can go to another employer; thus, they must be kept loyal by avoidance of coercion (which, much as the use of tight contracts, destroys trust) and by use of soft power (see Fox [1974] on power and trust relations).

Trust and control can be viewed as structures of inter-related situated practices that influence the development of different forms of expert power in particular organizational contexts. In this view, trust and control relations are generative mechanisms that play a role in the production, reproduction and transformation of expert power. Trust is based on predictability of behaviour, where some type of control or self-control mechanism influences such predictability. Trust and control are closely associated (Reed 2001; Maguire, Phillips and Hardy, 2001). Many organizations attempts to 'manage' trust as a means of control (Knights, Noble, Vurdubakis and Willmott, 2001). Maguire, Phillips and Hardy (2001) have suggested several ways in which this happens including actively manipulating the employee using rewards, acquiring information about the employee and thus rendering him/her

\footnotetext{
${ }^{6}$ Social capital as it is conceptualized most often in organization theory has three dimensions: structural, cognitive and relational. The discussion of structural and relational concepts is drawn from network theory, favoring separation. Structural elements comprise the overall patterns of connection (Burt 1992). These are to be found in the presence or absence of network ties, network configuration, and morphology, such as patterns of linkages. Density, connectivity and hierarchy characterize the linkages. Networks that are created for one purpose may be used for another (Nahapiet and Ghoshal 1998; Coleman 1988). The relational dimension of social capital captures references to assets created and leveraged through relationships. Among these are trust, trustworthiness, norms and sanctions, obligations and expectations, identity and identification. Relational embeddedness refers to the kind of personal relationship that people have, such as respect and friendship, which influence their behavior in fulfilling socially ascribed motives (Blum and McHugh 1971). The cognitive element refers to resources that provide shared representations, interpretation, and systems of meaning among parties (Nahapiet and Ghoshal, 1998).
} 
more predictable and hence controllable, and active manipulation of the goodwill of the employee by increasing his/her identification with the organization.

The rhetoric of 'trust' often sits uncomfortably in the context of all the routines constituting a 'low trust' workplace of design of technologies and of work by standardized procedures. Contemporary labour process studies carried out or reviewed by Thompson and Ackroyd (1995), Thompson and Ackroyd (1999) and Thompson and Warhurst (1998) suggest that we need to untangle the managerial rhetoric and intention with the realities of the situation.

\section{Managing knowledge}

Knowledge management is another new idea with deep roots that go back to Frederick Taylor and scientific management. Two aspects of knowledge management are relevant here. First, there is the treatment of knowledge as a commodity, through the mechanization and objectification of knowledge creation, diffusion, and storage. Treated this way it increases management's sense of control. Second, there is soft domination of the knowledge worker by identification-based control The highest degree of trust is when the person completely identifies with the organization, in which case his/her self-image is aligned with managerially determined objectives (Alvesson and Willmott, 2002). What knowledge management seeks to do is to draw from the tacit knowledge of individuals and the social capital of the group to construct new and improved routines. The thrust of scientific management and the many subsequent clones spawned from its political economy, such as knowledge management, was that routines produce increased efficiency where the correspondence between relations of knowledge is closed, where the worker does exactly what the scientific manager prescribes. Taylor and his heirs sought to make 
workers functionaries of knowledge relations defined externally to the 'being there' of the workers. Yet, paradoxically, as the Hawthorne Studies first revealed, efficiency is determined by the extent to which individual knowledge and expertise is accessed and utilized (Grant, 1996a: 380).

In the most current clone of scientific management—which is knowledge management - efficiency is based on common knowledge as a prerequisite to the communication of direction and routine. Translating specialist information depends on the sophistication and level of common knowledge. Second, the frequency and variability of task performance changes the efficiency of knowledge integration (Nelson and Winter 1982). The efficiency of comprehending and responding appropriately among employees involved in tasks is a function of frequency of task performance. Third, organizational structure that reduces the extent and intensity of communication to achieve integration assists efficiency and to do this the employee has to be integrated into the enterprise as an obedient rather than resistant subject. Knowledge management grows out of the cross-pollination of scientific management and human relations theory to make obedient subjects creative. ${ }^{7}$

\footnotetext{
${ }^{7}$ Not too creative though: it is a creativity that remains highly framed. Grant (1996b) identifies four mechanisms for accessing the creativity of, and simultaneously framing, specialized knowledge in organizations. The first three integrate knowledge while reducing the need and cost of communication and learning, while the fourth is dependent on interaction and cross-over learning in the decision process. The first mechanism stresses rules and directives involve direct forms of coordination (impersonal coordination including plans, schedules, forecasts, rules, policies, procedures, social norms and etiquette) and indirect forms (education and training) (de Boer, Van Den Bosch and Volberda 1999). Standardized information and communication systems are supposed to govern interaction and reduce the quantity of directions in communication necessitated by specialist knowledge and roles (Demsetz 1991; de Boer, Van den Bosch and Volberda 1999). Teece, Pisano and Shuen (1997: 520) press Mayo's discovery of culture into service by arguing that culture is a de facto governance system mediating the behavior of individuals. Second, sequencing activities and inputs allow individual specialist activity to be coordinated continuously, reducing communication. Activity independence varies depending on the product and technologies involved such as sequential, overlapping or concurrent. Third, routines as simple sequences of an automatic nature will be differentiated by supporting complex patterns of interactions among individuals, permitting transfer, recombination or creation of specialized (tacit) knowledge (Dyer and Nobeoka 2000). Highly interdependent, changes in one routine, or a higher-level system or architecture, result in new routines required to integrate and
} 
Knowledge management is an instrument producing new routines that result from acquiring and distilling knowledge of tacit experiences and action that is embedded in social and institutional practice (Spender et al, 1996; Brown and Duguid, 1991). Individual public performances draw on private parts of the self-the soul in Follett's terms - in interactions. Thus, as recent theory has it, 'the primary role of the firm is in integrating specialist knowledge resident in individuals into goods and services’ (Grant 1996b: 120). Knowledge management institutes what Garrick and Clegg (2000) have referred to as an 'organizational gothic' at the heart of organizational life, a capacity to suck the vitality from the individual body and soul in order to enhance the vitality of the corporate body for increased efficiency and reduced costs, through greater coactive power. The secret is in extracting creativity from the individual through the use of coactive power and instilling it into the body corporate, where the body corporate retains its vitality by sucking out the vitality of those members that compose it (Garrick and Clegg 2000). The allusion to Dracula is intended; the practice seems as gothic as any Hammer horror movie.

\section{Managing power/knowledge}

Individuals share uniquely held knowledge on the basis of what is held in common among them. Common knowledge refers to the 'common cognitive ground' among employees that facilitates knowledge transfer through promoting dialogue and communication (what Nonaka and Takeuchi [1995: 14] term redundancy).

coordinate related routines (Teece, Pisano and Shuen 1997). They occur between individuals in the absence of rules, directives or significant verbal communication and are expressed via a repertoire of responses (Grant, 1996b: 115). Fourth, group problem solving and decision-making supports low communication and direct transfer of knowledge arising from first three mechanisms. As task complexity increases, the need for interpersonal communication, interaction in decision-making and group input for non-standardized coordination also increases: meetings and open forums should be arranged in which consensus on unusual, complex and important tasks involving mutual adjustment can be achieved. Devices that decentralize knowledge integration serve to increase participation and thus increase the scope and flexibility of knowledge integration (de Boer, Van den Bosch, and Volberda 1999: 387). 
Redundancy creates an intentional overlap of information held by employees that facilitates transferring and integrating explicit and tacit knowledge. Knowledge about elements not directly related to immediate operational requirements that arises from images in tacit knowledge can be shared through redundant information about business activities, management responsibilities, the company, products and services (Nonaka and Takeuchi 1995: 81-82). Competitive, individuated, relations of power make this knowledge difficult to surface. Coercive power leads to zero-sum games, win/lose scenarios, power/resistance, and resource dependency (see chapter five). It creates power effects more akin to rape than seduction, as Nonaka and Takeuchi 1995argue. The rape and seduction analogy suggests that seduction would seek to elicit expert knowing representing a rich and anchored context, whereas rape absconds with the partial acquisition of knowledge without context, and thus, lacking situated meaning, promotes only a wrenching of something unwillingly given. That is why the projects of knowledge management and social capital are seeking to become aligned. First, use coactive power to seduce knowledge that can become the basis for the new routines. Then, when the new routines are established they take on a coercive power of their own, as individuals can be held accountable to them. The major problem with the knowledge management project is that we all carry a great deal of redundancy around in our heads. If you don't know what you know until you need to know it, how can you know what you have stored away in the junk room, so to speak, as 'redundant knowledge'? When the time is ripe relevant knowledge surges forth unbidden, but you cannot take an inventory of the 'redundant' when the time isn't ripe. There has to be someone knowing something in some context before knowledge can be known, let alone abstracted. The study of knowledge management should really be 
a study of power/knowledge management because its processes are indivisible from those of power:

At the core of management is the legitimation, extension, and normalization of dominant property rights, the practical disciplining of the everyday organizational life of members, and the framing of knowledge that can be ascribed a key role in extending, limiting, and otherwise shaping these rights. I call this the discourse of power/knowledge—a discourse that, in academic terms, functions as a surrogate for discussion of sovereignty (Clegg 2003: 536).

All forms of organization are forms of organization of social relations. All social relations involve power relations. Power is evident in relations not only of ownership and control but also of structuration and design. These relations take many forms. They may be embodied as financial capital, intellectual capital, or social capital. Such relations are likely to be both differentially distributed and socially constructed as well as exist in differential demand in differentiated markets. Power is also evident in the various forms of knowledge that constitute, structure, and shape these markets and organizations, what is referred to today as knowledge management. What is novel in knowledge management is its variation on the repertoire of scientific management is the orientation to the brain rather than the body, the fusion with the moral economy of social capital, and the combination of coactive with coercive power. It frames the new combinations of power/knowledge that are so evident in soft power today, as we will explore further in chapter twelve.

\section{Conclusion}

In management and organization theory power is embedded in practices that, very largely, do not theorize it as such. Little of what has been addressed as constituting the ‘standing conditions' legitimating regimes of power, entered greatly into 
subsequent accounts of power by management and organization scholars (Clegg et al 2006). Where it does so enter then it was as an assumption of 'authority', defined in terms of legitimate power, which could be safely bracketed as an unproblematic set of relations requiring no address. The marginalization of power was a trend strengthened further by the fillip that the Second World War gave to all matters related to personnel and organization design in the most advanced military of the day, the US forces, as well as in American factories involved in the war economy. In fact, power was being written into a corner where it was destined to become the antithesis, the other, to authority. The ascendance of a concern with authority went hand in hand with a view that resistance was counter productive and identified with organizational power; thus, power was expunged from authority. Perhaps this is one reason why the discourse of knowledge management has grown, so uncritically, with little or no address of power.

Bodies had been disciplined; new subjectivities were being constituted through new disciplines, frames, and practices that early pioneers talked and wrote into being. But, simultaneously with their talking and writing these practices into being there was a surprising silence about the nature of what was being created as, explicitly, practices of power. In large part this was because the intellectual apparatus that would enable one to make an explicit interpretation in power terms had yet to be constructed.

Formal acknowledgement of power, as a concept in its own right at the heart of organization practice, was something that waited in the wings where it had scuttled with the neglect of Follett's work for most of the century. The late translation of Max Weber's work into English from the late 1940s onwards saw it reappear but not in quite the way that its progenitor seemed to have intended. In the time and the space 
between scientific management and human relations, political and moral economy, after Weber but barely touched by his concerns, a concept of power emerged in theory, hesitantly, but with distinct characteristics, which, by and large, failed to address the historical constitution of power addressed in this chapter. When, from the 1970s onwards, the study of power and resistance developed out of labor process theory, the mechanics researched were very much work-place focused and missed the broader canvass on which these relations had already been prepared and constituted (see Fleming and Spicer 2007). Meanwhile, as I have argued elsewhere, the post-war theoretical mechanics of mainstream organization theory became increasingly fixated on power defined as deviations from authority (see Clegg et al 2006; Hardy and Clegg 2006), predicated on strategic resource control. What I have sought to do in this chapter is to capture some of the hidden history of power as it was constituted rather than merely provide a description of existing accounts which are, as I have argues elsewhere, fundamentally limited (Clegg et al 2006).

\section{References}

Abel, E. L. (1980) Marihuana: The First Twelve Thousand Years, New York: Plenum.

Alvesson, M. and Willmott, H. (2002) 'Identity Regulation as Organizational Control: Producing the Appropriate Individual'Journal of Management Studies, 39 (5), 619-644.

Appelrouth, S. (2005) 'Body and soul: Jazz in the 1920s', American Behavioral Scientist, 48(11): 1496-1509.

Baritz, L. (1974) The Servants of Power. A History of the Use of Social Science in American Industry, Westport, Connecticut, Greenwood Press. 
Bauman, Z. (1997) Postmodernity and its discontents, Cambridge, England: Polity, 1997

Bavelas, A. and Lewin, K. (1942) ‘Training in democratic leadership', Journal of Abnormal and Social Psychology, 52(1): 163 -176.

Blackler, F. (1995) 'Knowledge, Knowledge Work and Organizations: An Overview and Interpretation’, Organization Studies 16(6): 1021-1046.

Blum A. F. and McHugh, P. (1971) ‘The Social Ascription of Motives', American Sociological Review 36: 98-109.

Braverman, H. (1974) The Labor Process and Monopoly Capitalism, New York: Monthly Review Press.

Brown, J. S, and Duguid P. (2000) The Social Life of Information (Boston: Harvard Business School Press.

Brown, J. S., Duguid, P. (1991) ‘Organisational Learning and Communities of Practice: Toward a Unified View of Working Learning and Innovation, Organisation Science, 2: 40-57.

Burt, R. S. (1992) Structural holes: the social structure of competition, Cambridge, MA: Harvard University Press.

Canguilhem, G. 1992. Machine and Organism, pp.45-69 in J.Crary and S. Kwinter (eds.) Incorporations, New York: Zone Press.

Cartwright D. and Zander, A. (1953) Group Dynamics: Research and Theory, London: Tavistock.

Clegg, S. R. (2003), 'Managing Organization Futures in a Changing World of Power/Knowledge’ pp. 536 - 567 in The Oxford Handbook of Organization Theory, Tsoukas H. and Knudsen C. (eds.), New York: Oxford University Press. 
Clegg, S. R., Courpasson, D., and Phillips, N. (2006) Power and Organizations, Thousand Oaks, CA: Sage.

Cohen, S. (1972) Folk Devils and Moral Panics, London: Routledge.

Coleman, J. S. (1988) 'Properties of rational organisations', pp $79-90$ in S. M. Lindenberg and $\mathrm{H}$ Schreuder (eds.), Interdisciplinary Perspectives on Organisation Studies, Oxford: Oxford University Press.

Dale, K. (2001) Anatomising embodiment \& organization theory, London: Palgrave.

Dandeker, C. (1990) Surveillance, Power and Modernity: Bureaucracy and Discipline from 1700 to the Present Day, Cambridge: Polity.

de Boer, M. Van den Bosch, F. A. J. and Volberda, H. W. (1999) 'Managing Organisational Knowledge Integration in the Emerging Multimedia Complex’, Journal of Management Studies, May, 36(3): 379-398

Demsetz, H. (1991) ‘The Theory of the Firm Revisited', pp 159 -178 in O.E. Williamson and S. Winter (eds.), The Nature of the Firm, Oxford University Press, New York.

Douglas, M. (1966) Purity and Danger, London: Routledge \& Kegan Paul.

Dyer, J. H. and Nobeoka, K. (2000) 'Creating and Managing a High-Performance Knowledge-Sharing Network: The Toyota Case, Strategic Management Journal, 21: 345-367.

Fleming P. and Spicer, A. (2007) Contesting the corporation, Cambridge: University of Cambridge Press.

Foucault, M. (1977) Discipline and Punish: The Birth of the Prison. London: Allen \& Lane.

Fox, A. (1974) Beyond Contract: Work, Trust and Power, London: Tavistock Press. Garrick, J. and Clegg, S. R. (2000) 'Organizational Gothic: Transfusing Vitality and 
Transforming the Corporate Body through Work-based Learning', pp153 -171

in C. Symes and J. McIntyre (eds) Working Knowledge: The New

Vocationalism and Higher Education, Buckingham: The Society for Research into Higher Education and Open University Press.

Goffman, E. (1961) Asylums, Harmondsworth: Penguin.

Gramsci, A. (1971) From the Prison Notebooks, London: Lawrence and Wishart.

Grant, R. M (1996a) 'Prospering in Dynamically Competitive Environments:

Organisational Capability as Knowledge Integration’, Organisational Science, July-August, 7(4): 375-387.

Grant, R. M, (1996b) ‘Toward a Knowledge-Based Theory of the-Firm’, Strategic Management Journal, 17: 109-122.

Hardy, C., and Clegg, S. R. (1996) 'Some Dare Call it Power.’ pp. 622-641 in Stewart R. Clegg, Cynthia J. Hardy and Walter R. Nord (Eds.) The Handbook of Organization Studies. London: Sage.

Haugaard, M. (1997) The constitution of power, Manchester: Manchester University Press.

Hoskin, K. and Macve, R. (1988) 'The Genesis of Accountability: the West Point Connections', Accounting, Organizations and Society, 13, 1: 37-73.

Ibarra-Colado, E. (2001a) 'Foucault, gubernamentalidad y organización: una lectura de la triple problematización del sujeto’, in Iztapalapa, 21(50): 321-358.

Jacques, R. (1996) Manufacturing the Employee: Management Knowledge from the $19^{\text {th }}$ to $21^{\text {st }}$ Centuries, Thousand Oaks, CA: Sage.

Kanigel, R., (1997) The one best way: Frederick Winslow Taylor and the enigma of efficiency, New York: Viking. 
Kogut, B. and Zander, U. (1996) 'What Do Firms Do? Coordination, Identity and Learning', Organisation Science, 7: 502-518.

Kolb, D. (1986) The critique of pure modernity: Hegel, Heidegger and after, Chicago: University of Chicago Press.

Lee, A. (1980) Henry Ford and the Jews, New York: Stein and Day.

Lopes, P. (2005) 'Signifying deviance and transgression: Jazz in the popular imagination', American Behavioral Scientist, 48(11): 1468-1481.

Maguire, S., Phillips, N., \& Hardy, C. (2001).When silence = death, keep talking: trust, control and the discursive construction of identity in the Canadian HIV/AIDS treatment domain. Organisation Studies, 22(2), 285-310.

Marcus, A. and Segal, H. P. (1989) Technology in America, New York: Harcourt Brace Johanovitch.

Maslow, A. H. (1978) ‘A Theory of Human Motivation’, pp. 27-41, in Victor H. Vroom and Edward L. Deci (eds.), Management and Motivation, Harmondsworth, Penguin Books.

Mayo, E. (1933) The Human Problems of an Industrial Civilization, New York: Viking.

Mayo, E. (1975) The Social Problems of an Industrial Civilization, London: Routledge and Kegan Paul.

Meyer, S. (1981) The Five Dollar Day: Labor Management and Social Control in the Ford Motor Company, 1908-1921. Albany: State University of New York Nahapiet, J. Ghoshal, S. (1998) 'Social Capital, Intellectual Capital and the Organisation Advantage', Academy of Management Review, 23(2): 2-266.

Nelson, D. (1975) Managers and Workers: Origins of the New Factory System in the United States, 1880-1920, Madison: University of Wisconsin Press. 
Nelson, R.R. and Winter, S.G. (1982) An Evolutionary Theory of Economic Change, Cambridge, MA, Harvard University Press, Belknap Press.

Nonaka, I. and Takeuchi, H. (1995) The Knowledge Creating Company Oxford: Oxford University Press.

Porter, E. (2002) What Is This Thing Called Jazz? African American Musicians as Artists, Critics, and Activists, Berkeley: University of California Press.

Putnam, R. D. (1993) 'The Prosperous Community: Social Capital and Public Life’, American Prospect, 13: 35-42

Putnam, R. D. (1995) ‘Bowling Alone: America’s Declining Social Capital’, Journal of Democracy, 6: 65-78

Reed M. J. (2001) 'Organization, trust and control: a realist analysis', Organization Studies, 22 (2), 201-228.

Rose, N. (1989) Governing the Soul, London: Routledge.

Rose, N. (1996) Inventing Our Selves: Psychology, Power, and Personhood, Cambridge: Cambridge University Press.

Sayer, D. (1991) Capitalism and Modernity: An Excursus on Marx and Weber; London: Routledge.

Spender, J. C. and Kijne, H. J. (eds.) (1996) Scientific management: Frederick Winslow Taylor's gift to the world? Boston: Kluwer Academic Publishers.

Taylor, F. W. (1911) Principles of Scientific Management, New York: Harper.

Teece, D. J. Pisano, G. and Shuen, A. (1997) ‘Dynamic Capabilities and Strategic Management', Strategic Management Journal, 18(7): 509-533

Thompson, P. and Ackroyd, S (1995) ‘All Quiet on the Workplace Front? A Critique of Recent Trends in British Industrial Sociology Sociology 59(4): 615-633 
Thompson, P. and Warhurst, C. (Eds ) (1998) Workplaces of the Future London: Macmillan.

Trahair, R. (2001) ‘George Elton Mayo’, Biographical Dictionary of Management, Thoemmes Press: http://www.thoemmes.com/

Turner, B. S. (1984) The body and social theory, Oxford: Blackwell.

van Krieken, R. (1990) 'The Organisation of the Soul: Elias and Foucault on discipline and the self', Archives Europeénes de Sociologie, 31(2): 353-71.

Watts, S. L. (1991) Order against Chaos: Business Culture and Labor Ideology in America 1880-1915, New York, Greenwood Press.

Yates, J. (1989) Control through communication: the rise of system in American management, Baltimore: Johns Hopkins University Press. 